\title{
ПРОЕКТУВАННЯ ТЕСТОВИХ ЗАВДАНЬ ЗАКРИТОГО ТИПУ НА БАЗІ МОДЕЛІ ОНТОЛОГІЇ НА ОСНОВІ КОГНІТИВНИХ ПРОТОТИПІВ
}

\author{
О. А. Рижов, А. М. Попов \\ Запорізький державний медичний університет
}

\begin{abstract}
Роботу присвячено вирішенню актуальної проблеми автоматизованого проектування тестових завдань закритого типу в медико-біологічній предметній галузі на основі формальної моделі онтології на базі когнітивних прототипів. Авторами розроблена універсальна трирівнева модель онтології на основі когнітивних структур та виділений патерн знань, названий когнітивним прототипом, як структуру даних для репрезентації учбових знань на основі таких когнітивних структур як поняття, концепт, фрейм, схема, сценарій. В статті наведено фрормальний опис тестових завдань на основі когнітивних прототипів та їх типізацію як перший крок до розробки алгоритмів їх автоматизованої генерації та розробки підсистеми генерації тестових завдань закритого типу в авторській системі ІСДНКП (Інтелектуальна система дистанційного навчання на основі когнітивних прототипів). Проаналізовано перспективи такого підходу для розробки уніфрікованих методик до проектування тестів з одночасним зниженням трудомісткості процесу підготовки до їх автоматизованої генерації.
\end{abstract}

Ключові слова: когнітивний прототип, дистанційне навчання, інтелектуальна навчальна система, тестові завдання, автоматизована генерація.

\section{ПРОЕКТИРОВАНИЕ ТЕСТОВЫХ ЗАДАНИЙ ЗАКРЫТОГО ТИПА НА БАЗЕ МОДЕЛИ ОНТОЛОГИИ НА ОСНОВЕ КОГНИТИВНЫХ ПРОТОТИПОВ}

\author{
А. А. Рыжов, А. Н. Попов \\ Запорожский государственный медицинский университет
}

\begin{abstract}
Работа посвящена решению актуальной проблемы автоматизированного проектирования тестовых заданий закрытого типа в медико-биологической предметной области на основе формальной модели онтологии на базе когнитивных прототипов. Авторами разработана универсальная трёхуровневая модель онтологии на основе когнитивных структур и был выделен паттерн знаний, названный когнитивным прототипом, как структура данных для репрезентации учебных знаний на основе таких когнитивных структур как понятие, концепт, фрейм, схема, сценарий. В статье предложено фрормальное описание тестовых заданий на основе когнитивных прототипов и их типизация как первый шаг к разработке алгоритмов их автоматизированной генерации и разработки подсистемы генерации тестовых заданий закрытого типа в авторской системе ИСДНКП (Интеллектуальная система дистанционного обучения на основе когнитивных прототипов). Проанализированы перспективы такого подхода для разработки унифицированных методик проектирования тестов с одновременным снижением трудоемкости процесса подготовки к их автоматизированной генерации.
\end{abstract}

Ключевые слова: когнитивный прототип, дистанционное обучение, интеллектуальная обучающая система, тестовые задания, автоматизированная генерация.

\section{DESIGNING OF MULTIPLE-CHOICE TESTS ON THE BASIS OF AN ONTOLOGY BASED ON COGNITIVE PROTOTYPES}

\author{
O. A. Ryzhov, A. M. Popov \\ Zaporozhye State Medical University
}

\begin{abstract}
The paper is devoted to resolving a topical issue of automatized tests production in poor-formalized knowledge domains. An approach was proposed to carry out an automatized generation of multiple-choice tests on the basis of an ontological model of a domain based on prototypes of human cognitive structures. The universal ontological three-level model was developed with the core element called "cognitive prototype" as a data structure for knowledge representation in form of such known cognitive structures as concept, frame, scheme, scenario, etc. The formal description of test patterns was devised based on cognitive prototypes as the first step towards their typification, developing of algorithms of their automatized generation and programming of subsystem of intelligent educational systems. Prospects of such approach have been
\end{abstract}

(C) О. А. Рьжов, А. М. Попов 
analyzed for designing unified techniques of tests production with reduction of laboriousness of the test preparation process.

Keywords: cognitive prototype, e-learning, intelligent educational system, multiple-choice tests, automatized generation.

Вступ. Тестування є одним із найпоширеніших та найефективніших сучасних засобів достовірної оцінки якісних та кількісних параметрів навчальних досягнень студентів. Однією з проблем є висока трудомісткість їх розробки для оцінки рівня засвоєння певних понять або учбових об' єктів навчальної предметної галузі. Авторська розробка тестових завдань 3 наступною валідацією на експертній комісії досі залишається основним механізмом забезпечення навчального процесу засобами контролю та перевірки знань. Сучасні інформаційні технології дозволяють частково вирішувати проблеми автоматизованої генерації тестів з використанням одного з таких підходів, як побудова поняттєво-тезисної моделі (ПТМ), в якій формалізація навчального тексту відбувається шляхом виділення семантико-дидактичних елементів у навчальному тексті [2], або онтологічний підхід, який використовує онтологічну модель предметної галузі у термінах мови OWL, наприклад ODT (Ontology for Test Design), розробленої у лабораторії японського дослідника R. Mizoguchi $[11,12]$. Такі технології переважно використовуються у добре формалізованих предметних галузях та залишаються недостатньо ефективними у малоформалізованих, таких як медико-біологічна. Крім того, недоліком таких підходів є суттєві обмеження у варіації типів тестових завдань, які згенеровано, а також необхідність володіти достатньо складними технологіями побудови онтологій та мовами розробки, якими переважно не володіють викладачі вищих навчальних закладів медико-біологічного профілю. Успіхи когнітивної лінгвістики та когнітивної психології щодо пошуку механізмів сприйняття та засвоєння знань людиною [4], які спонукали нас до пошуку універсального патерну репрезентації знань, дозволяють поповнити процес генерації тестових завдань теоретичною базою та практичними провадженнями.

Мета дослідження. Метою роботи було провести аналіз можливостей автоматизованого проектування тестових завдань на основі онтологічної моделі предметної галузі, у основу якої покладено структуру когнітивного прототипу, сформувати формальні патерни та надати їх типізацію.

Теоретичні передумови. Дослідження процесів пізнання та навчання характеризується широкими міжпредметними зв'язками, які сьогодні досліджу- ються такими науковими напрямами як психологія (О. Харві, У Скотт, Х. Шродер, Д. Хант, У Найссер, Е. Рош), психофізіологія, лінгвістика, теорія штучного інтелекту (М. Мінський), епістемологія (J. О. Мікешина І. П. Меркулов) які, у свою чергу, об'єднуються в єдину когнітивну науку. Предметом дослідження цього наукового напряму є когнітивна система, яка інтегрує в процесі діяльності, спрямованої на рішення своїх цільових завдань, такі компоненти як мозок людини або біологічної системи і довкілля, в якому система існує. Одним з найвагоміших припущень когнітивного підходу є наявність так званих «когнітивних структур особистості»у свідомості людини, на основі яких Грунтуються процеси сприйняття, засвоєння та зберігання інформації. Професор В. Ф. Петренко, лідер нового напрямку російської психології «експериментальна психо семантика», дає таке визначення когнітивних структур: «.. .когнітивні структури особистості являють собою узагальнено-типізовані системи організації знань, що є одночасно механізмами вилучення, використання і зберігання інформації» [1]. Когнітивна лінгвістика та когнітивна філософія розрізняють такі когнітивні структури як поняття, концепти, фрейми, об'єкти, гештальт, схема. Доцільність дослідження можливостей застосування когнітивних структур для організації та репрезентації навчального та контролюючого матеріалу аргументується тим, що для підвищення якості навчання необхідний аналіз механізмів засвоєння інформації.

Основна частина. Онтологічний підхід широко використовується для репрезентації навчального матеріалу та генерації тестових завдань відкритого і закритого типів у сучасних інтелектуальних системах комп'ютерного навчання. Проте онтології, розроблені у термінах мови OWL, не враховують психологічну складову репрезентації знань, тому не можуть бути ефективними на рівні сприйняття навчального матеріалу. Крім того, специфіка інструментарію унеможливлює розробку таких онтологій та використання засобів генерації контролюючих елементів викладачем - непрофесіоналом у технічній предметній галузі. У попередніх роботах нами було запропоновано універсальну структуру даних для репрезентації та накопичення таких когнітивних структур як поняття, концепт, фрейм, сценарій, названу когнітивним прототипом [8]. Для цього була 
розроблена універсальна трирівнева модель представлення навчальних знань на основі синтезу онтологічного підходу і когнітивних структур (рис. 1): 1-й рівень - термінологічний (для репрезентації навчальних понять і термінів), 2-й рівень - мережевий (для визначення зв'язків між поняттями) і 3-й рівень - структурний (для репрезентації об'єктів на основі КС). Універсальність запропонованої моделі полягає також в тому, що поняття усіх типі в можуть мати структуру, тобто бути вузлами дерева понять свого типу. При цьому поняття «об'єкт» може розглядатися в локальних контекстах і також бути учасником різних автономних дерев, в яких воно розкрите порізному, залежно від складності і повноти опису ПрГ. Відмінністю від аналогічних та головною особливістю моделі є те, що на рівні репрезентації інформації ми використовуємо когнітивні структури для підвищення якості сприйняття навчального матеріалу. При цьому кожним вузлом онтології в заданому контексті $\epsilon$ екземпляр класу або об'єкт, в якому, з одного боку, заключена інформація про положення об'єкта усередині семантичної мережі або його «координати».
Задавши список батьківських понять, а також список дочірніх понять ми отримуємо назву об'єкта в поточному контексті. 3 іншого боку, повне уявлення про об'єкт - його назва, статичні характеристики i його поведінка або методи дослідження. Побудована таким чином онтологія дозволяє організувати знання предметної галузі на однорідних структурах, що відкриває багато можливостей для автоматизованої генерації навчальних на контролюючих елементів.

Необхідність створення науково обгрунтованої методики розробки тестових завдань обумовлена, поперше, потребою скоротити час та витрати на розробки тестів та аналіз результатів тестування, подруге, необхідністю забезпечити розробників тестів методикою, та, по-третє, розробити системи автоматизованої генерації, сумісні з існуючими інтелектуальними системами комп'ютерного навчання. Класичний тест $є$ послідовністю запитань, на кожне 3 яких $є$ відповідь, яка може бути перевірена й оцінена як правильна, неправильна або частково правильна (наприклад, неповна) [10].

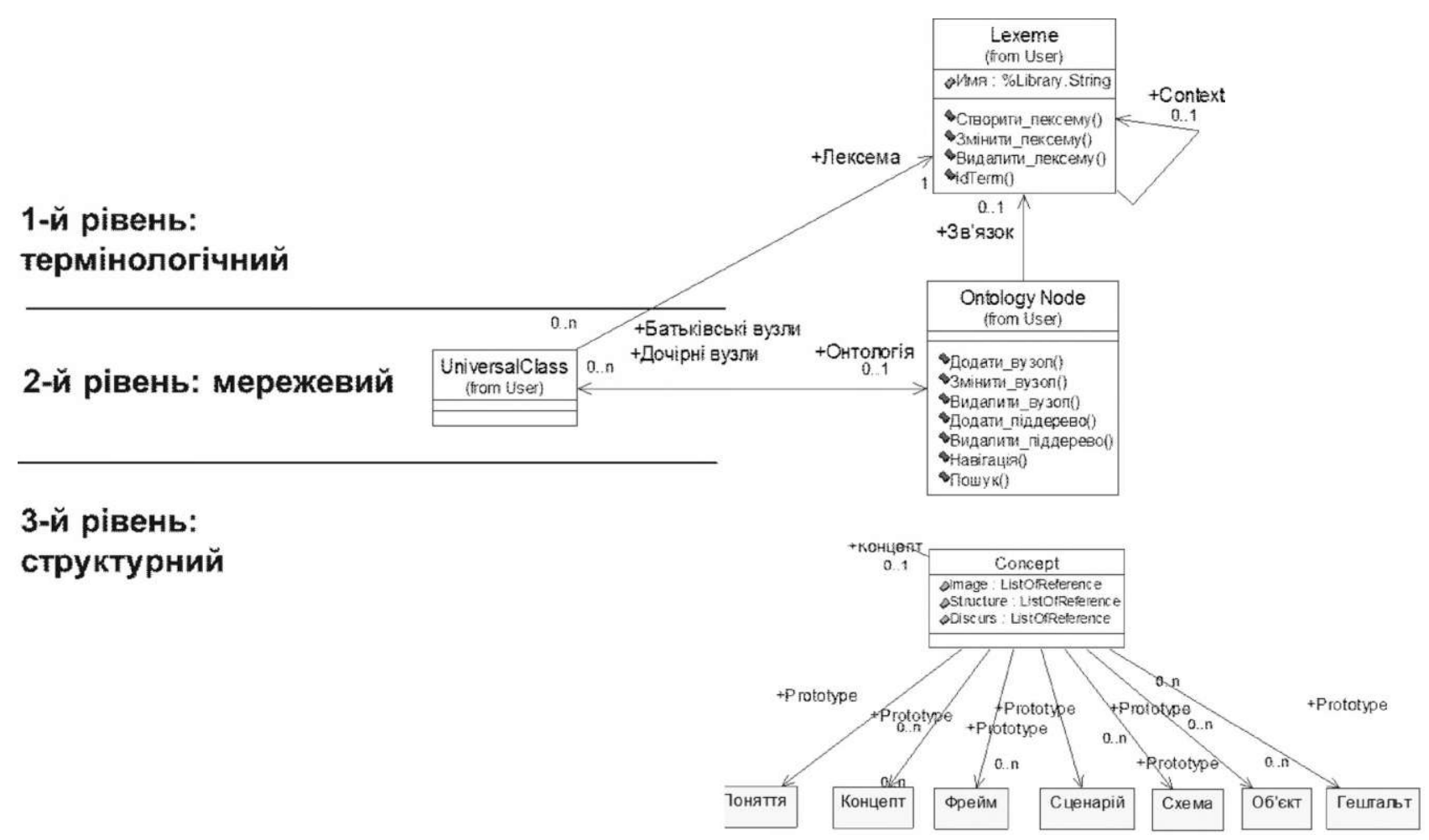

$\boldsymbol{P u c , ~ 7 . ~ У н і в е р с а л ь н а ~ т р и р і в н е в а ~ м о д е л ь ~ о н т о л о г і і ̈ , ~ у ~ в у з л а х ~ я к о і ̈ ~ з н а х о д я т ь с я ~ к о г н і т и в н і ~ с т р у к т у р и . ~}$

Форми тестових завдань можуть бути досить різноманітними, зокрема, дослідник В. М. Распопов пропонує 24 форми тестових завдань [5]. Завдання 3 вибором однієї правильної відповіді, кількох правильних відповідей, з градуйованими відповідями, на встановлення правильної послідовності $\epsilon$ 
найбільш дослідженими, але при цьому рівень технологій, які здатні формувати запитання такого класу, є недостатнім і потребує подальшого дослідження. В наших попередніх роботах запропоновано технологію побудови еталонної моделі предметної області на основі синтезу онтологічного підходу та когнітивних прототипів та запропоновано формальну модель когнітивного прототипу для формування патернів тестових завдань. Модель онтології бази знань, побудованої на основі когнітивних прототипів, може бути представлена за допомогою трійки (1) [6, 7, 8, 13]:

$C P=<$ Object, Link, Cognitive SubGroup $>$, (1) де Object - поняття або учбовий об'єкт, який вивчається; Link - тип семантичного відношення (нами виділено п'ять базових типів семантичних відношень таких як «рід-вид», «частина-ціле», «об'єкт-ознака», «об'єкт-стан», «об'єкт-функція»), Cognitive SubGroup - набір елементів (лексем) когнітивної підгрупи, пов'язаних з Object за допомогою Link.

У даній роботі запропоновано підхід для проектування тестових вправ закритого типу. Метою нижченаведених патернів тестів є перевірка знань студентів щодо якісного складу навчальних об'єктів, рідвидових стосунків (когнітивна структура «поняття»), характерних ознак, функцій та станів досліджуваних об'єктів (когнітивна структура «об'єкт/фрейм»). Нижче наведено типізацію тестових завдань закритого типу на основі КП. Питання групи А (ідентифікація об'єкта як цілого, складеного 3 компонентів; ідентифікація об'єкта як суттєво сті, яка виконує чітко окреслений набір функцій тощо.).

\section{\#A}

Ідентифікуйте об'єкт, який поєднаний з елементами когнітивної підгрупи <SubIteml, Subltem2, ... SubItemN > за допомогою зв'язку типу $<$ Link $>$.

$\%$ ! $100 \%<$ TrueObject $>$;

$\%$ oO $\%<$ FalseObj ect $>$;

$\% \mathrm{oO} \%<$ FalseObj ect $>$;

$\% \mathrm{oO} \%<$ FalseObj ect $>$;

$\%$ oO $\%<$ FalseObj ect $>$;

Дистрактори для питань такого типу обираються iз множини суміжних понять поточної теми, або попередніх тем з урахуванням типу зв'язку. Подальша деталізація питань такого типу можлива шляхом специфікації питань з урахуванням типу семантичного відношення. Наприклад, для зв'язку типу «частинаціле», удосконалене формулювання питання буде: «Ідентифікуйте об'єкт, сполучений із елементів, наведених в списку <Objectl, Object $2, \ldots$ Object $\mathrm{N}>$. Наведемо приклад з медичної паразитології:
«Ідентифікуйте учбовий об'єкт, сполучений із елементів, наведених в списку \{"Сколекс", "Шийка", "Проглотиди" \}"

$\%$ ! $100 \%<$ Cestoidea $>$

$\% 0 \%<$ Aranei $>$;

$\% 0 \%<\operatorname{lnsecta}>$;

$\% 0 \%<$ Acarina $>$;

У прикладі дистрактори отримані з вузлів онтології, які належать до попередніх тем курсу «Паразитологія».

\#B

Оберіть зайві елементи когнітивної підгрупи об'єкта <Object>, поєднані за допомогою зв'язку $<$ Link $>$. (N вірних відповідей та $\mathrm{M}$ дистракторів, усього опцій $\mathrm{Y}=\mathrm{N}+\mathrm{M})$

$\% 0 \%<$ TrueItem $>$;

$\% 50 \%<$ FalseItem $>$;

$\% 0 \%<$ TrueItem $>$;

$\% 0 \%<$ TrueItem $>$;

$\% 50 \%<$ FalseItem $>$;

Питання такого типу можуть бути вирішені частково (студентові може бути зараховано 1/2, 1/3 бала тощо за неповну вірну відповідь), та, як у попередньому випадку, можуть бути вдосконалені шляхом специфікації за типом зв'язку. Наприклад, для вузлів iз зв'язком типу «об'єкт-функція», перефразоване питання може бути: «Оберіть функції, нетипові для об'єкта < Object>». Наведемо приклад 3 медичної паразитології:

Оберіть методи діагностики не типові для об'скта <Асагіпа>:

$\% 0 \%<$ мікроскопія зскрібка шкіри>;

$\% 50 \%<$ біопсія м'яза $>$;

$\% 0 \%<$ мікроскопія вмісту волосяної сумки>;

$\% 0 \%<$ мікроскопія вмісту вугра $>$;

$\% 50 \%<$ імунологічні реакціi $>$;

У прикладі дистрактори отримані з вузла Nematoda. Повною відповіддю (100\%) на питання є обидві опції «біопсія м'яза» та «імунологічні реакції» які не є типовими методами дослідження вказаного об'єкта.

\section{\#C (ЗВоРОТня В)}

Оберіть пропущені елементи когнітивної підгрупи $<$ Iteml, Item $2, \ldots$ ?> об'єкту < Object $>$, поєднані за допомогою зв'язку $<$ Link $>$. ( $\mathrm{N}$ вірних відповідей та М дистракторів, усього опцій $\mathrm{Y}=\mathrm{N}+\mathrm{M}$ )

$\% 0 \%<$ FalseItem $>$;

$\% 30 \%<$ TrueItem $>(\%)$;

$\% 0 \%<$ FalseItem $>$; $(\%)$

$\% 30 \%<$ TrueItem $>(\%)$;

$\% 30 \%<$ TrueItem $>(\%)$;

$\% 0 \%<$ FalseItem $>(\%)$; 
Дистрактори для питань такого типу обираються 3 множини елементів когнітивної підгрупи суміжних понять поточної теми, або попередніх тем з урахуванням типу зв'язку у найпростішому випадку випадковим чином. Для вузлів із зв'язком типу «об'єкт-ознака», перефразоване питання може бути: «Доповніть перелік ознак (симптомів захворювання, зовнішніх ознак тощо), які є характерними для об'єкта $<$ Object $>$, <Featurel, Feature2, ... ?>». Як у попередньому випадку, наведемо приклад з медичної біології, розділу «Медична паразитологія».

«Доповніть перелік зовнішніх ознак, які є характерними для об'скта < Strongiloides stercolaris $>$, <«ниткувате тіло», «довжина <=2мм»,... ?>»

$\% 0 \%<$ Локалізуються у очах $>$;

$\% 50 \%<3$ акруглена передня частина тіла $>(\%)$;

$\% 0 \%<$ Самки наживо родючі $>$; $(\%)$

$\% 50 \%<$ Конічна задня частина тіла $>(\%)$;

$\% 0 \%<$ Яйця безбарвні овально-симетричні $>(\%)$;

Дистрактори відібрано 3 навчальних об'єктів «Enterobius vermicularis», «Brugia malayi» та «Nematoda».

ш

Ідентифікуйте тип семантичного зв'язку між об'єктом $<$ Object $>$ та списком елементів когнітивної підгрупи $<$ Iteml, Item2, ... ItemN>.

$\% 0 \%<$ FalseBand $>$;

$\%$ ! $100 \%<$ TrueBand $>$;

$\% 0 \%<$ FalseBand $2>$;

$\% 0 \%<$ FalseBand $3>$;

$\% 0 \%<$ FalseBandN $>$;

Приклад:

Ідентифікуйте тип семантичного зв'язку між об'єктом <Anoplura> та списком елементів когнітивної підгрупи < «Pediculus humanus capitis», «Pediculus humanus corporis», «Phthirus pubis»>.

$\% 0 \%<$ Частина-ціле $>$;

$\%$ ! 100\%<Рід-вид>;

$\% 0 \%<0$ б' єкт-ознака $>$;

$\% 0 \%<0$ б' єкт-метод>;

$\% 0 \%<0$ б' єкт-стан $>$;

Ми бачимо такий тип тестових завдань найлегшим, який може використовуватися у режимі навчання на етапі самостійної роботи.

Дискусія. Ми навели чотири типи тестових завдань, які можуть бути автоматично згенеровані 3 формальної структури КП як елемента навчальної онтології та оцінили рівень їх складності. Для оцін- ки варіації питань можна підрахувати їх кількість виходячи із кількості базових семантичних відношень (5 семантичних відношень, 16 формувань). Загальну кількість тестових завдань нескладно підрахувати за формулами комбінаторики з урахуванням загальної кількості КП по кожній темі та з предмета в цілому. Можливе також тонке налаштування під окрему предметну галузь на етапі підготовки до генерації, наприклад, якщо очевидно, що навчальними об'єктами мають бути «Паразити людини», то на підготовчому етапі ми можемо замінити патерн питання, та надати викладачеві-оператору системи інструмент для редагування вихідного шаблону. Наприклад заміна [«об'єкт»]-> [«паразит»] у контексті «Медична паразитологія». Запропонований підхід піднімає також питання валідності генерованих тестів. Проте це питання більше стосується валідності онтології, на основі якої буде відбуватися генерація тестових завдань. В такому випадку, якщо доведено валідність онтології та обгрунтовано алгоритм генерації, тестові завдання автоматично стають валідними.

Висновки. Формальна структура КП дозволяє автоматично генерувати тестові завдання закритого типу.

1. Проаналізовано можливості побудови тестових завдань на основі моделі онтології ПрГ на основі формальної структури когнітивного прототипу. Встановлено, що на основі когнітивного прототипу можуть бути генеровані завдання тестового типу чотирьох типів. Кількість дистракторів до кожного питання обирається зважаючи на потрібну складність тесту.

2. Перевагами запропонованих шаблонів $є$ формалізовані патерни, при розробці алгоритмів генерації, процес генерації тестів може бути виконаний викладачем, без залучення експертів зі створення тестів; порівняно невеликі трудові і часові витрати необхідні для підготовки тесту;

Перспективи дослідження. Перспективи дослідження полягають у розробці алгоритмів автоматичної генерації тестів описаних типів і розробці модулів навчання та контролю знань у системі ІСДНКП [13], проведенні дослідження з оцінки ефективності контролюючих тестів подібного типу перед впровадженням методів оцінки та контролю знань у навчальний процес вищого медичного навчального закладу. 


\section{Література}

1. Петренко В. Ф. Психо семантика сознания/В. Ф. Петренко. - М. : Изд-во МГУ, 1988. - 234 с.

2. Петрова ЈI. Г. Використання модифікованої понятійнотезисної моделі для автоматизованого формування бази тестових запитань в системах комп'ютеризації освіти / JI. Г. Петрова, С. А. Петров // Інформаційні технології і засоби навчання. - 2012. - № 4 (3О). - С. 1-13.

3. Попов А. М. Ефективність виконання комп'ютерногенерованих вправ 3 дисципліни «Інформаційні технології в фармації» на основі когнітивних прототипів / А. М. Попов // Медична інформатика та інженерія. - 2014. - № 4. - С. 91-98.

4. Попова 3. Д. Когнитивная лингвистика / 3. Д. Попова, И. А. Стернин. - М. : АСТ, Восток-Запад, 2007. - 315 с. 5. Распопов В. М. Программирование и организация самостоятельной работы учащихся/В. М. Распопов.-М.: Высш. шк., 1989.-55 с.

6. Рижов О. А. Інваріантна модель подання знань у системах дистанційного навчання на основі об'єктно орієнтованого підходу / О. А. Рижов, А. М. Попов // Медична інформатика та інженерія. - 2010. -№ 1. - С. 100-109.

7. Рыжов А. А. Алгоритмы формирования учебных элементов на основе структуры универсального класса объектов в интеллектуальных системах обучения / А. А. Рыжов, А. Н. Попов // Сборник работ Первого Всеукраинского съезда «Медична та біологічна інформатика і кібернетика» с международным участием - К. : Изд. НМАПО им. П. Л. Шупика, 2010. - С. 120.
8. Рыжов А. А. Когнитивный прототип как практический базис для структуризации и представления учебных декларативных знаний в ИСДО / А. А. Рыжов, А. Н. Попов // Клиническая информатика и Телемедицина. - 2012. - № 1. - С. 133-138.

9. Титенко С. В. Генерація тестових завдань у системі дистанційного навчання на основі моделі формалізації дидактичного тексту/С. В. Титенко//Наукові вісті НТУУ «КПІ». - 2009. - № 1 (63). - C. 47-57.

10. Brusilovsky P. and Miller P. Web-based testing for distance education. In: P. De Bra and J. Leggett (eds.) Proceedings of WebNet'99 // World Conference ofthe WWW and Internet, Honolulu, HI, Oct. 24-30. - 1999. - AACE. - P. 149-154.

11. Soldatova L. An ontology-based test generation system / L. Soldatova, R. Mizoguchi // Semantic Web Technologies for e-Learning. - 2009. - P. 96-112.

12. Nkambou R. Advances in Intelligent Tutoring Systems / J. Bourdeau, R. Mizoguchi - Heidelberg: Springer Verlag, Studies in Computational Intelligence, - 2010. - Vol. 308, 510 pp.

Ryzhov A. Web-oriented Educational System for Supporting Students' Learning Activity Based on Cognitive Prototypes / A. Ryzhov, A. Popov // International Journal of e-Education, e-Business, e-Management and e-Learning. - 2014. -Vol. 4., No. 4. - P. 310-320. Available form: http://www.iieeee.org/ Papers/346-JZ0073.pdf 